\title{
Characterization of Nanohydroxyapatite isolated from Seer Fish Bones and Waste Scales and its Applications in Lead Removal
}

\author{
Vanavil B, Yoka Barrathi N S
}

\begin{abstract}
Hydroxyapatite, (HA), $\mathrm{Ca}_{10}\left(\mathrm{PO}_{4}\right)_{6}(\mathrm{OH})_{2}, \quad$ is recognized as a biomaterial and extensively used for bone implant because of its structural and chemical similarity with mineral components of enamel and human bone. The elements of $\mathrm{HA}$ are largely composed of calcium and phosphorus molar ratio of 1.67 and is capable of promoting bone in-growth into prosthetic implant. Huge amounts of by-product waste generated from fish processing industry and market generated an undesirable environmental impact. In this perspective, the present study focused on the isolation and characterization of nanohydroxyapatite ( $\mathrm{nHA}$ ) from bones and waste scales of seer fish. Tissue removal process was carried out by boiling bones and scales at $100^{\circ} \mathrm{C}$ for 4-5 hours and further boiling with acetone and sodium hydroxide. $\mathrm{nHA}$ was isolated by alkaline hydrolysis treatment. The isolated $\mathrm{nHA}$ was characterized by Fourier Transform Infrared Spectroscopy (FT-IR), Scanning Electron Microscopy (SEM) - Energy Dispersive Spectroscopy (EDS). FT-IR spectrum disclosed the presence of functional groups of HA. SEM-EDS revealed the size shape and elemental composition of the isolated $\mathrm{nHA}$. Further, the application of this isolated $\mathrm{nHA}$ in removal of lead was also investigated. At elevated $\mathrm{pH}$ levels, $\mathrm{nHA}$ adsorbed the lead ions effectively with reduction in lead ions greater than 95\%. These results suggest that nHA isolated from bones and waste scales of seer fish can be potentially used for waste water treatment.
\end{abstract}

Keywords: Alkali Treatment, Lead removal, Nanohydroxyapatite, Seer fish

\section{INTRODUCTION}

Hydroxyapatite (HA) is the most widely used for orthopaedic and dental reconstruction as it is a predominant component of human bone mineral and teeth enamel. To date, HA implants have been clinically used in the form of powders, granules, cements, dense and porous blocks, biphasic, coatings and composites. Depending on the synthesis route and HA powder processing conditions, various other calcium phosphates with $\mathrm{Ca} / \mathrm{P}$ ratio ranging from 2.0 to as low as 0.5 can be produced. HA is generally highly crystalline with the following lattice parameters: $(a=0: 95 \mathrm{~nm}$ and $\mathrm{c}=0: 68 \mathrm{~nm})$ and it displays a hexagonal symmetry with preferred

Revised Manuscript Received on December 05, 2019

* Correspondence Author

B. Vanavil*, Department of Biotechnology, Kalasalingam Academy of Research and Education, Krishnankoil, India.

N.S. Yoka Barrathi, Department of Biotechnology, K.S.Rangasamy College of Technology, Tiruchengode, India. orientation along the $\mathrm{c}$ axis. HA crystals typically display a needle-like morphology [1].

Synthetic HA is stoichiometric with a chemical formula of $\mathrm{Ca}_{10}\left(\mathrm{PO}_{4}\right)_{6}(\mathrm{OH})_{2}$, and a specific atomic $\mathrm{Ca} / \mathrm{P}$ molar ratio of 1.67 [2]. HA finds applications in bone tissue engineering, bone void filling for orthopedic, traumatology, spine, maxillofacial and dental surgery, orthopedic and dental implant coating, reinforcing restorative glass ionomer cement (GIC) and restorative composite resin, desensitizing agent in post teeth bleaching, remineralizing agent in toothpastes, early carious lesions treatment, drug and gene delivery, biocatalysis, adsorption. Hydroxyapatite coatings and titanium coatings are capable of connecting structurally and functionally with human bone. HA is biocompatible, bioactive, osteoconductive, non-toxic and possess non-inflammatory and non-immunogenic properties making it suitable as biomaterial [3].

HA can be either produced by synthetic means or obtained from natural sources. However, HA extracted from natural sources are ecological and holds improved metabolic activity compared to the synthetic counterpart. Likewise, stoichiometry of synthetic HA is equivalent to the stoichiometry of pure HA yet it does not have any minerals such as $\mathrm{Mg}$, Na, F, $\mathrm{K}$ and $\mathrm{Cl}$ that are found in natural sources. During the reconstruction of bone fractures, these minerals restore osteoconductive properties of HA. Moreover, the process of producing synthetic HA is normally expensive, complicated, and time consuming [4].

India generates more than 2 million metric tonnes of by-products from fish processing activities. Fish waste is considered as insignificant trash and generally discarded without recovery of any useful product. Most of the fish by-products are presently used to produce fish meal, fish silage, fertilizer, pet food and fish oil. Fish bones are primarily composed of $30 \%$ of collagen as an organic matter and the remaining is inorganic with sodium, magnesium and hydroxyapatite. Recent studies have documented numerous bioactive compounds like hydroxyapatite present in remaining fish muscle proteins, fish oil, gelatin, collagen, fish bones, internal organs, fish scales, shellfish and crustacean shells [4]. 
Lead is a heavy metal, well known for toxicity upon exposure and its accumulation can cause severe health effects in human. Lead is released into environment during mining, smelting, use of leaded paint, leaded gasoline, leaded aviation fuel, lead-acid batteries and lead pipes. As per water quality standards, lead in water must be in the range of $0.05-0.1 \mathrm{mg} / \mathrm{L}$. As stated by the Indian Standard Institution, the tolerance limit of lead in drinking water is $0.05 \mathrm{mg} / \mathrm{L}$ and for surface waters is $0.1 \mathrm{mg} / \mathrm{L}$ (ISI, 1982). Abnormalities such as hepatitis, mental retardation, fall in the production of haemoglobin may result with presence of lead more than $0.5-0.8 \mu \mathrm{g} / \mathrm{mL}$ in blood. It affects body metabolism, I.Q. levels in children and has been classified by the IARC as a $2 \mathrm{~B}$ carcinogen. Exposure of high levels of lead to pregnant women to can cause miscarriage, stillbirth, premature birth and low birth weight. Keeping these in view, removal of lead from the waste water prior is must before discharging [5].

In this perspective, the present study focused on isolation and characterization of nanohydroxyapatite (nHA) from bones and waste scales of seer fish. Further, the application of isolated nHA in removal of lead under batch conditions was also reported.

\section{MATERIALS AND METHODS}

\section{A. Collection and processing of Samples}

Seer Fish (Scomberomorus guttatus) and waste scales were obtained from the local fish market located at Srivilliputhur, Tamil Nadu. They were thoroughly washed to remove undesired particles present in the samples.

\section{B. Preparation of Seer Fish Bones and Waste Scales}

Flesh was removed from fish and the bony parts were cooked using boiling water for 30 minutes whereas scales were washed thoroughly. Unwanted flesh stuck with the bones were removed and were kept in $1 \mathrm{~L}$ of boiling water for 3 hours. After 3 hours, 1 L of distilled water was again added and boiled to remove all the tissue remnants. Further, the samples were boiled in $50 \mathrm{~mL}$ of acetone and $50 \mathrm{~mL}$ of $2 \%$ $\mathrm{NaOH}$ for 1 hour. Then the solutions were continuously flushed with water to ensure tissue removal and dried at $60^{\circ} \mathrm{C}$ in hot air oven until the moisture is removed completely [6].

\section{Isolation of Hydroxyapatite from Seer fish bones and waste scales}

Nanohydroxyapatite (nHA) was isolated from the Seer fish bones and scales using alkaline hydrolysis method. Crushed bones and scales were heated with $2 \mathrm{M} \mathrm{NaOH}$ for 1 hour at $100^{\circ} \mathrm{C}$. This process was repeated until all the traces of organic and collagenous material was removed. Nanohydroxyapatite particles were collected and centrifuged at $1000 \mathrm{rpm}$ for 5 minutes, Then the particles were washed with distilled water until $\mathrm{pH}$ value reaches 8.5 and further dried to remove the moisture completely [6].

\section{Characterization of nHA}

\section{1) Fourier Transform Infrared Spectroscopy}

Presence of functional groups and infrared spectrum resolution frequencies of the nanohydroxyapatite obtained from Seer fish bones and waste fish scales was recorded within the range of 400 to $4000 \mathrm{~cm}^{-1}$ using IR Tracer -100 , Shimadzu Fourier Transform Infrared Spectrophotometer [6].

\section{2) Scanning Electron Microscopy and Energy}

Dispersive X-ray Spectroscopy

The size and shape of the nHAs were revealed using Scanning Electron Microscope (SEM) (EVO - 18 Bruker, Germany). Selected areas within the SEM sections were subjected to elemental composition analysis using Energy Dispersive X-ray Spectroscopy (EDS) (Bruker 6130, Germany) coupled with SEM [6].

\section{E. Adsorption Experiments for Lead Removal}

The efficiency of isolated nHA in removal of lead was studied using adsorption experiments. Batch sorption experiments were executed by preparing a stock $\mathrm{Pb}(\mathrm{II})$ solution containing $1 \mathrm{~g} / \mathrm{L}$ of $\mathrm{Pb}\left(\mathrm{NO}_{3}\right)_{2}$. Then $100 \mathrm{ml}$ of working solution containing $20 \mathrm{mg} / \mathrm{L}$ of $\mathrm{Pb}$ (II) was prepared by diluting the stock solution with distilled water. Effect of initial $\mathrm{pH}$ on adsorption process was studied by changing $\mathrm{pH}$ of the lead solution $(100 \mathrm{mg} / \mathrm{L})$ in the range of $\mathrm{pH} 3-10 \mathrm{using}$ $5 \%$ nitric acid $\left(\mathrm{HNO}_{3}\right)$ or $5 \%$ sodium hydroxide $(\mathrm{NaOH})$. $0.05 \mathrm{~g}$ of nHA isolated from bones and scales were added to $50 \mathrm{ml}$ of each lead solution of different $\mathrm{pH}(20 \mathrm{mg} / \mathrm{L})$ and was incubated in the rotary shaker for about 6 hours. Then samples were removed, centrifuged at $8000 \mathrm{rpm}$ for 10 minutes [7] and quantitatively tested for lead ions present using AA-7000 model Atomic Absorption Spectrophotometer.

\section{RESULTS AND DISCUSSION}

\section{A. Isolation of nHA from Seer Fish bones and Waste Scales}

Fish wastes are discarded by local fish markets and industries that can impose environmental and health risks to the people. In turn, these wastes can be used for extraction of value added products that have a wide range of applications. Hydroxyapatite is one such compound that can be isolated from the fish wastes. With potential applications in biomedicine, dentistry, drug delivery and waste water treatment, fish bones and scales serves as cheap source hydroxyapatite. Taking this into consideration, the present study involved the use of seer fish bones and waste fish scales for the production of hydroxyapatite.

A visible color change was observed in bones after alkali treatment. Bones turned into light yellow color from white color, whereas, scales lost its firmness and it remained in the same color. The solvents used for alkali treatment turned yellow, and this indicates the organic matter removal from the bones and scales (Fig. 1).

\section{B. Characterization of $\mathbf{n H A}$}

1) Fourier Transform Infrared Spectroscopy

Fourier Transform Infrared Spectroscopy (FT-IR) is used for identification of chemical bonds in a molecule by producing an infrared absorption spectrum. Fig. 2a, 2b depicts the 
FT-IR spectrum of bones and scales and nHA isolated from these respectively.
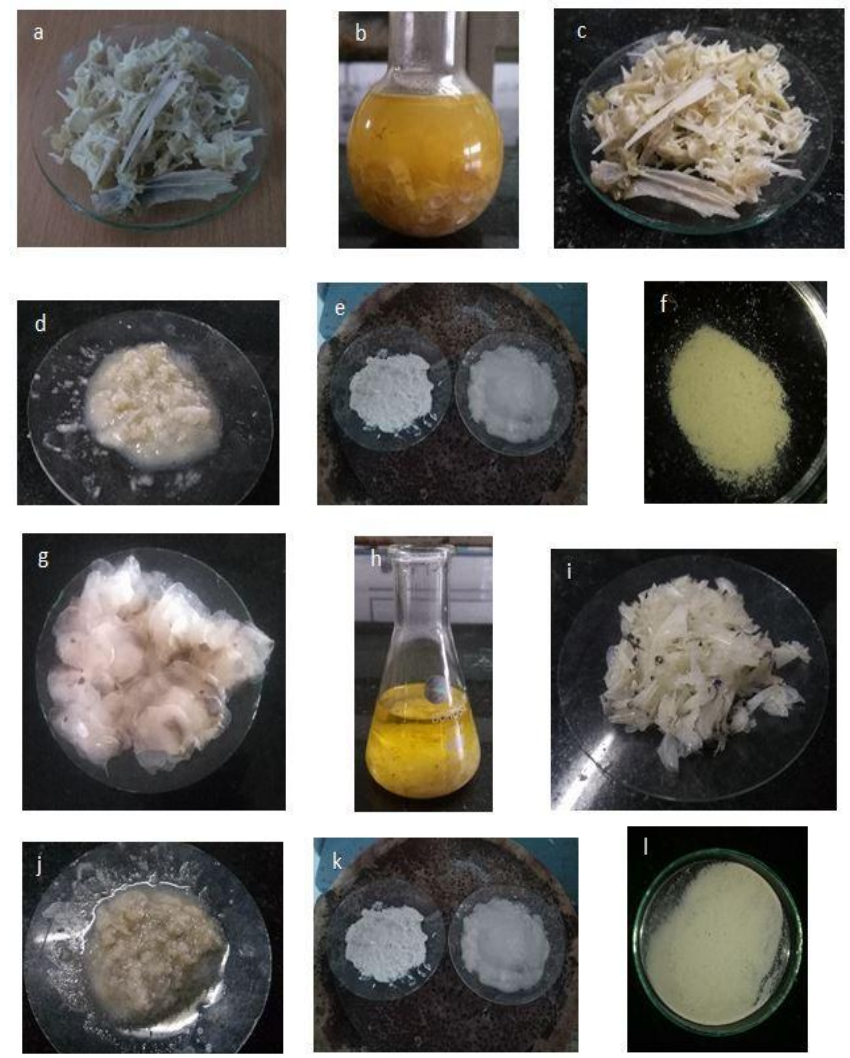

Fig. 1. (a) Raw Seer fish bones (b) Alkali treatment of bones (c) Bones after alkali treatment (d) Bones after grinding (e) Drying of $n \mathrm{HA}$ isolated from bones $(f) \mathrm{nHA}$ isolated from bones (g) Raw Scales (h) Alkali treatment of scales (i) Scales after alkali treatment (j) Scales after grinding (k) Drying of $n \mathrm{HA}$ isolated from scales $(l) \mathrm{nHA}$ isolated from scale.

Nanohydroxyapatite isolated from Salmon fish bones were analyzed by FT - IR spectrum [6]. FT-IR spectra of crushed bones (Fig. 4a) showed a band at $1745 \mathrm{~cm}^{-1}$. This band indicates the presence of tissues in the sample. No such band was observed in the range of $1700 \mathrm{~cm}^{-1}$. So, indicating the maximum tissue removal. However, presence of collagen was indicated by bands at $1417.68 \mathrm{~cm}^{-1}$ and $1556.55 \mathrm{~cm}^{-1}$. Remarkable difference was observed in the FT-IR spectrum of nHA isolated from bones and scales, before and after alkali treatment. Several bands were absent in the FT-IR spectrum of nHA compared to bones and scales.

In case of bones, the characteristic bands were observed at $565.14 \mathrm{~cm}^{-1}, \quad 603.72 \mathrm{~cm}^{-1}, 873.75 \mathrm{~cm}^{-1}, 1033.85 \mathrm{~cm}^{-1}$, $1417.68 \mathrm{~cm}^{-1}, 2833.43 \mathrm{~cm}^{-1}, 2885.51 \mathrm{~cm}^{-1}, 3423.65 \mathrm{~cm}^{-1}$ and $3697.57 \mathrm{~cm}^{-1}$. Band at $1417.68 \mathrm{~cm}^{-1}$ indicates the presence of carbonated group (A and B type).

Fig. $2 \mathrm{~b}$ depicts the FT-IR spectra of scales before alkaline treatment and nHA isolated from scales. In case of scales before alkali treatment signal at $1745 \mathrm{~cm}^{-1}$ was not observed indicating the absence of tissue. Organic matter present in the sample was indicated by signal at $1649.14 \mathrm{~cm}^{-1}$. Presence of carbonated groups was confirmed by signal at 1417.68 $\mathrm{cm}^{-1}$. Band at $1649.14 \mathrm{~cm}^{-1}$ was not observed in FT-IR spectrum of scales after alkali treatment indicating the complete removal of organic matter from scales. The characteristic bands for nHA were observed at $565.14 \mathrm{~cm}^{-1}$, $603.72 \mathrm{~cm}^{-1}, 873.75 \mathrm{~cm}^{-1}, 2839.22 \mathrm{~cm}^{-1}$ and $3699.47 \mathrm{~cm}^{-1}$.

\section{2) SEM-EDS mapping}

Fig. 3 (a, b, c and d) depicts the SEM images of fish bones and scales, before and after alkali treatment (HA). From the figures it can confirmed that the hydroxyapatite particles were of irregular rod shape with nano size $(17.58 \mathrm{~nm})$.

Compositional analysis of the bone and scale samples before and after alkali treatment showed that there was significant difference in the quantity of elements present. A hike in $\mathrm{Ca}$ and $\mathrm{P}$ were observed in the samples after alkali treatment. $13 \%$ increase in $\mathrm{Ca}$ and $5 \%$ increase in $\mathrm{P}$ was observed in the samples of bones while $1 \%$ increase in $\mathrm{Ca}$ and $\mathrm{P}$ was observed in the samples of scales after alkali treatment. It can be inferred that, alkali treatment enhances $\mathrm{Ca}$ and $\mathrm{P}$, particularly in case of bones. Since these two elements are the major components of nHA, alkali treatment can be preferred for the synthesis of nHA. Figure $4 \& 5$ shows the EDS mapping of fish bones and scales before and after treatment respectively.

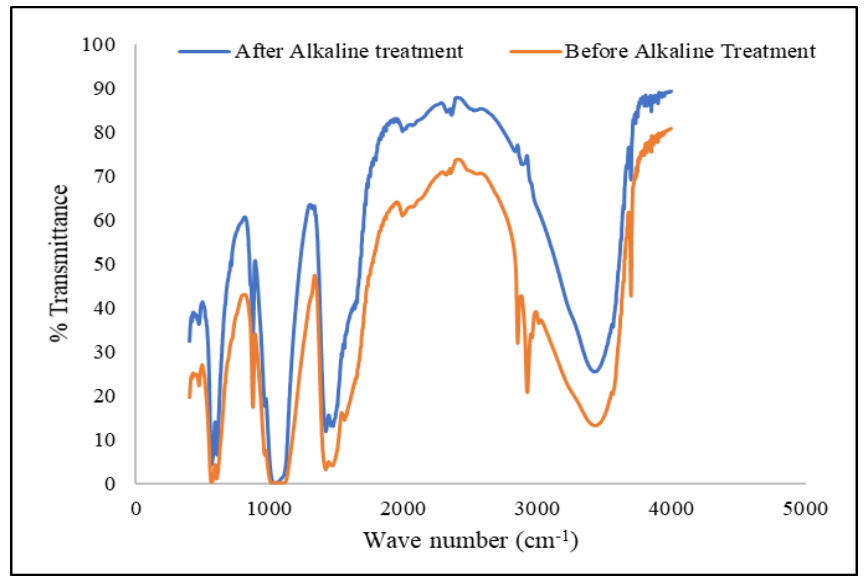

Fig. 2a. FT-IR Spectrum of Nanohydroxyapatite isolated from Seer Fish Bones.

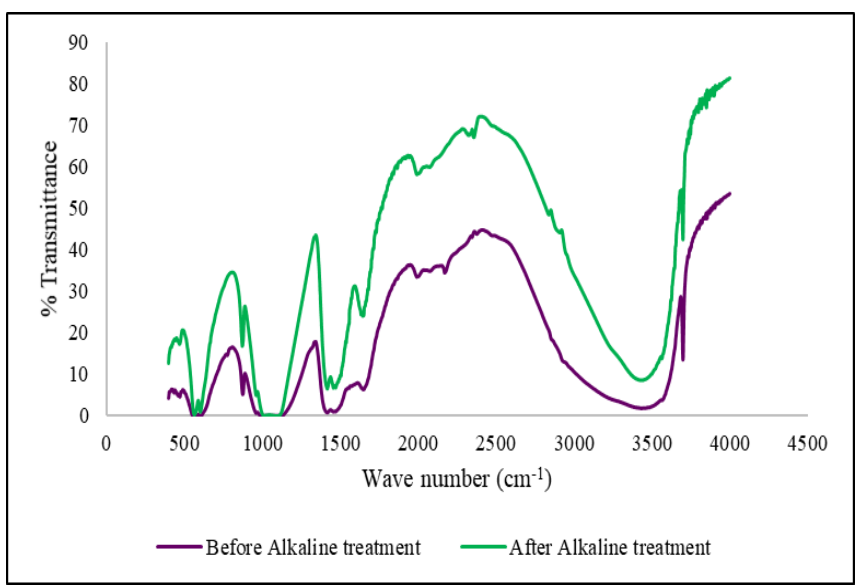

Fig. 2b. FT-IR Spectrum of Nanohydroxyapatite isolated from Waste Scales 

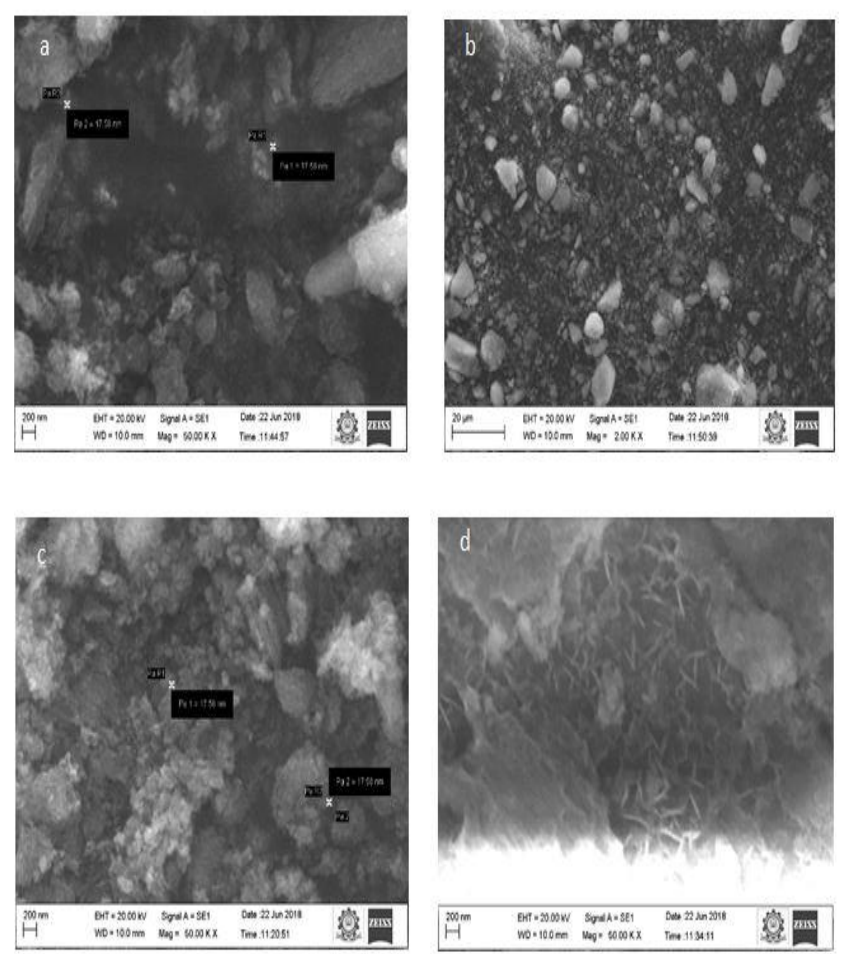

Fig. 3. Scanning Electron Microscopic images of fish bones (a \& b) before and after alkali treatment, Scales (c \& d) before and after alkali treatment
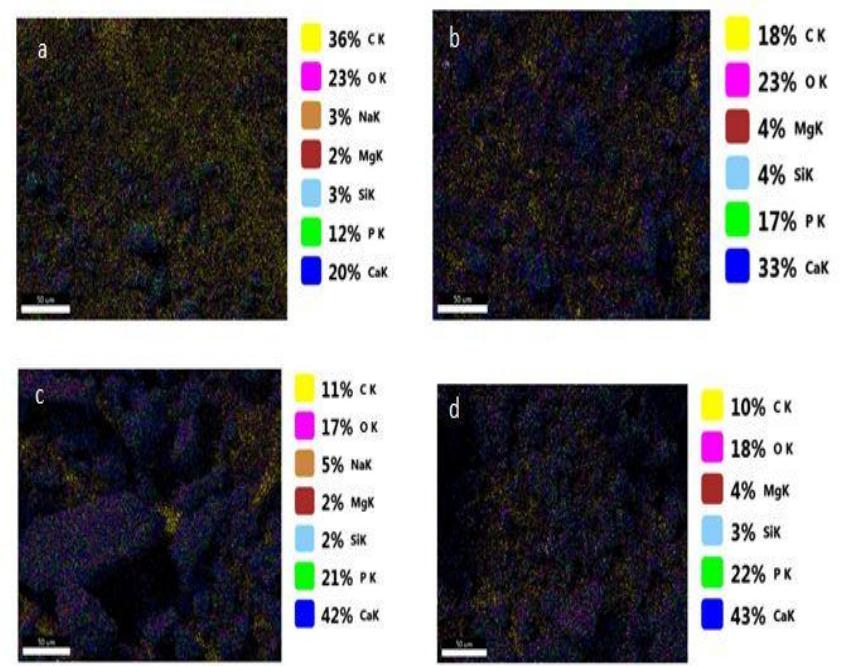

Fig. 4. Elemental Composition of (a) before alkali treatment of bones (b) after alkali treatment of bones (c) before alkali treatment of scales (d) after alkali treatment of scales

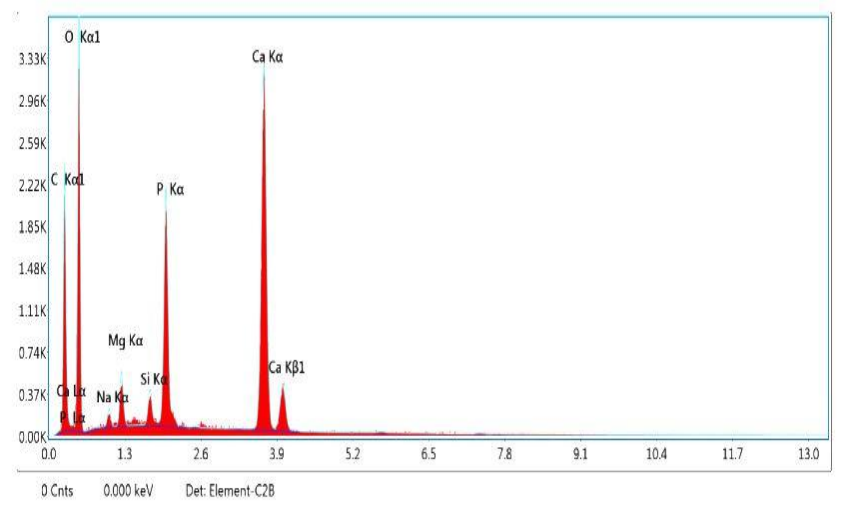

Fig.5a. Mapping of elements present in particles before alkali treatment of Seer fish bones

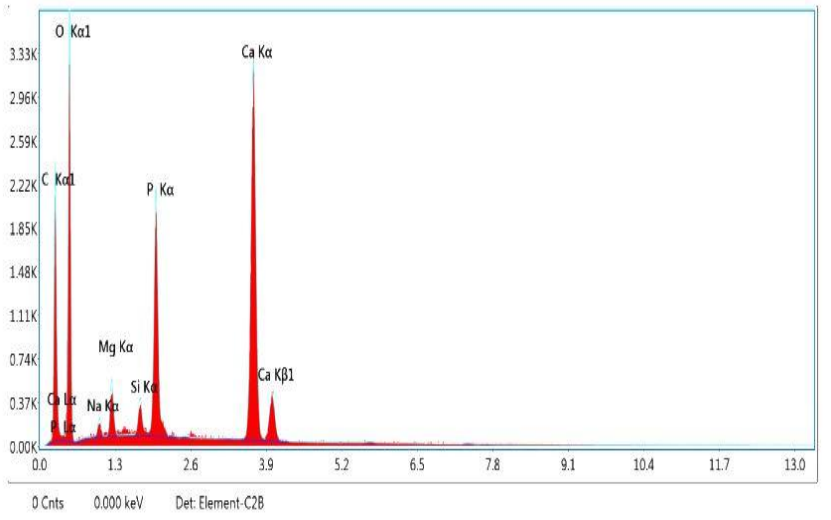

Fig.5b. Mapping of elements present in particles after alkali treatment of Seer fish bones

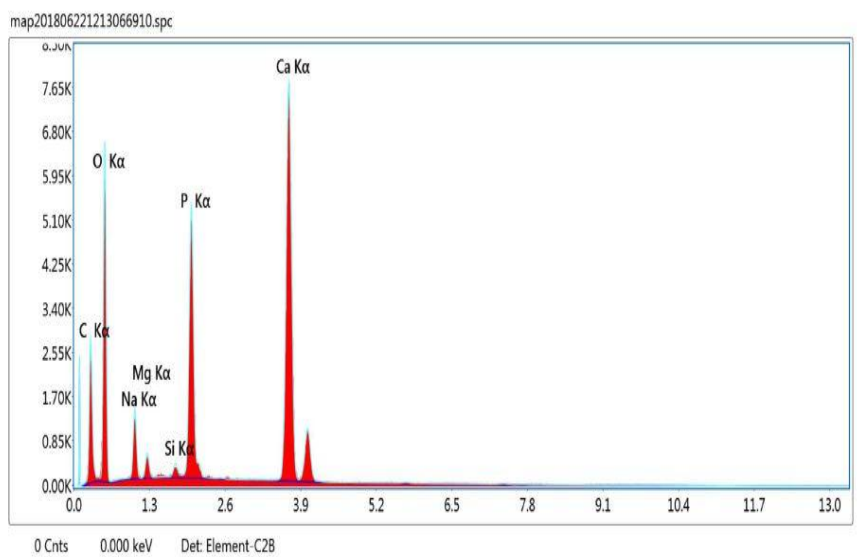

Fig.5c. Mapping of elements present in particles before alkali treatment of waste scales

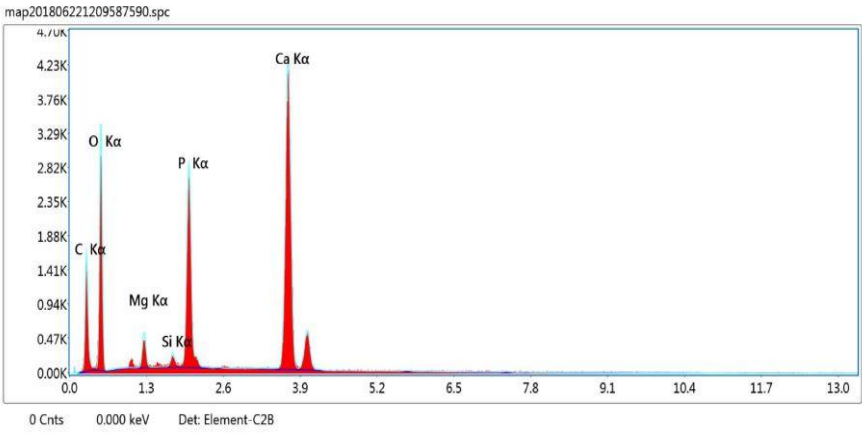

Fig.5d. Mapping of elements present in particles after alkali treatment of waste scales

\section{Applications of nHA in Lead Adsorption}

Quantification of lead ions present in the lead solution before and after treatment with nHA were calculated using AAS from the calibration graph (Fig. 6). Percentage of lead reduction in each sample treated with $\mathrm{nHA}$ at different $\mathrm{pH}$ was calculated using (1):

$$
\% \text { reduction of leadions }=\frac{\left[\mathrm{Le}_{\mathrm{c}}-\mathrm{Le}_{\mathrm{a}}\right]}{\mathrm{Le}_{\mathrm{c}}} \times 100
$$

$\mathrm{Le}_{\mathrm{c}}-$ Amount of Lead ions present in Control

$\mathrm{Le}_{\mathrm{a}}$ - Amount of Lead ions present after adsorption

Table I shows the percentage reduction of lead ions using 
nHA as adsorbent. Absorption capacity of nHA decreased with the increase in the $\mathrm{pH}$ of the solution up to 5 . The percentage reduction of lead ions reduced sharply at alkaline $\mathrm{pH}$ as evident from the Table I.
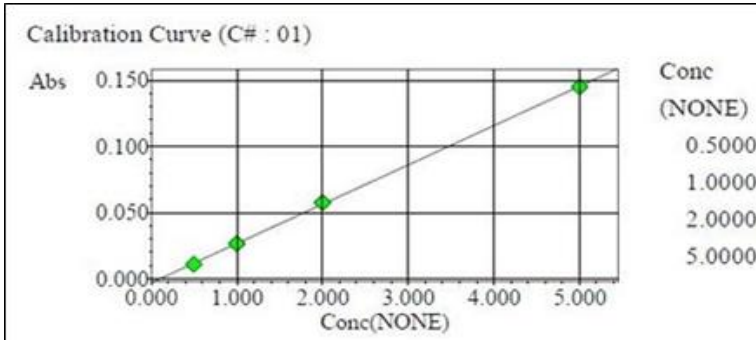

Abs $=0.029715$ Conc -0.003044

$\mathrm{r}=0.9999$

Fig. 6. Calibration Curve for Lead ions

TABLE - I: Percentage reduction of lead ions present in different samples.

\begin{tabular}{|c|c|c|c|c|c|}
\hline \multirow{2}{*}{$\begin{array}{c}\text { pH of } \\
\text { lead } \\
\text { solution }\end{array}$} & \multicolumn{3}{|c|}{ Pb (ppm) } & \multicolumn{2}{c|}{$\begin{array}{c}\text { \% reduction of } \\
\text { lead ions }\end{array}$} \\
\cline { 2 - 6 } & Control & $\begin{array}{c}\text { After } \\
\text { adsorption } \\
\text { by Scales }\end{array}$ & $\begin{array}{c}\text { After } \\
\text { adsorption } \\
\text { by Bones }\end{array}$ & Scales & Bones \\
\hline 3 & 13.274 & 0.0991 & 0.3649 & 99.25 & 97.25 \\
\hline 4 & 11.659 & 0.2000 & 0.2000 & 98.28 & 98.28 \\
\hline 5 & 0.6510 & 0.1765 & 0.2606 & 72.89 & 59.97 \\
\hline 10 & 0.7419 & 0.4726 & 0.4491 & 36.3 & 39.46 \\
\hline
\end{tabular}

\section{CONCLUSION}

Nanohydroxyapatite were isolated from Seer fish bones and waste scales by alkali treatment method. Isolated nHA was characterized by FT-IR and SEM-EDS mapping. Further, the application of isolated nHA in removal of lead by adsorption was studied. More than $90 \%$ reduction in lead ions was obtained through biosorption using nHA at $\mathrm{pH} 3$ and 5 . With the increase in the $\mathrm{pH}$, the percentage reduction was found to decrease. Hence it can be concluded that the isolated nanohydroxyapatite can be potentially used in treatment of waste water containing heavy metals. Further, this nHA isolated from seer fish bone and scales can be employed for various biomedical applications in future.

\section{ACKNOWLEDGMENT}

We would like to acknowledge the support provided by International Research Centre (IRC), Kalasalingam Academy of Research and Education (KARE) for FT-IR, Atomic Absorption Spectroscopy and Scanning Electron Microscopy - Energy Dispersive X-ray Spectroscopy (EDS) analysis. Ms. N S Yoka Barrathi thanks KARE for providing Summer Student Visiting Internship (2018-2019) to perform this work at Department of Biotechnology, KARE.

\section{REFERENCES}

1. V. S. Gshalaev and A. C. Demirchan, Eds., Hydroxyapatite: synthesis, properties, and applications. Hauppauge, N.Y: Nova Science Publishers, August 2012. Available : http://hdl.handle.net/10204/6469.
2. M. Akram, R. Ahmed, I. Shakir, W. A. W. Ibrahim, and R. Hussain, "Extracting hydroxyapatite and its precursors from natural resources," Journal of Materials Science, vol. 49, no. 4, pp. 1461-1475, Febrauary 2014. DOI: https://doi.org/10.1007/s10853-013-7864-X.

3. Gabriel, "Hydroxyapatite," The nano-hydroxyapatite specialist FLUIDINOVA. Available

https://www.fluidinova.com/hydroxyapatite-properties-uses-and-applicat ions/31-hydroxyapatite.

4. A. N. K. A. Fara and H. Z. Abdullah, "Characterization of derived natural hydroxyapatite (HAp) obtained from different types of tilapia fish bones and scales," presented at the PROCEEDINGS OF THE 23RD SCIENTIFIC CONFERENCE OF MICROSCOPY SOCIETY MALAYSIA (SCMSM 2014), Tronoh, Malaysia, 2015, p. 020077. July 2015. URL : https://doi.org/10.1063/1.4919215.

5. A. Kaushal, S.K. Singh, Adsorption phenomenon and its application in removal of lead from waste water: a review, Int J Hydro. vol. 1, no. 2, pp. 38-47, 2017, July 2017. DOI: 10.15406/ijh.2017.01.00008.

6. J. Venkatesan et al., "Isolation and Characterization of Nano-Hydroxyapatite from Salmon Fish Bone," Materials, vol. 8, no. 8, pp. 5426-5439, August 2015. DOI: 10.3390/ma8085253.

7. R. Morsy, "Synthesis and physicochemical evaluation of hydroxyapatite gel biosorbent for toxic $\mathrm{Pb}(\mathrm{II})$ removal from wastewater," Arabian Journal for Science and Engineering, vol. 41, no. 6, pp. 2185-2191, June 2016.

https://doi.org/10.1007/s13369-015-1893-5.

DOI

\section{AUTHORS PROFILE}

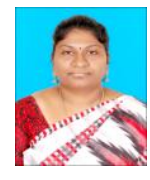

Dr. B. Vanavil received her Ph.D. from National Institute of Technology, Tiruchirappalli, Tamilnadu, India. Currently, she is working as faculty in the Department of Biotechnology, Kalasalingam Academy of Research and Education, Krishnankoil. She has published several papers in international journals and conference proceedings. Her research areas include Bioprocess Optimization, Modeling, Simulation, Control and biomaterials for medical applications. She is a life member of ISTE and a recipient of Young Scientist Fellowship of Tamilnadu State Council for Science and Technology.

Ms. N S Yoka Barrathi, did her post-graduation in Biotechnology at K.S.Rangasamy College of Technology, Tiruchengode. She was a student member of IEEE EMBS and recipient of IEEE - Student Project Funding (2016). Her research interests are biomaterials, and gene editing using CRISPR/Cas9. 